\title{
Enhancing the quality of end-of-life care in Canada
}

\author{
Deborah Cook MD, Graeme Rocker DM, Daren Heyland MD
}

$\mathrm{C}$ urrently, approximately 240000 Canadians die each year, about $90 \%$ as a result of a prolonged illness. Given our aging population, it is estimated that by 2020 there will be $40 \%$ more deaths annually than in $2003 .{ }^{1}$ For dying Canadians, there are well-documented gaps between the end-of-life care people prefer and the care that they actually receive. Narrowing these gaps is a pressing public and professional priority.

Improving the concordance between desired and provided end-of-life care will require more honest and timely conversations about goals of care with patients, their families and the members of their health care team. Recently, 278 acutely ill elderly Canadians with advanced chronic disease and their families were interviewed in 12 hospitals. ${ }^{2}$ Over three-quarters of patients had thought about end-of-life care and had discussed it with a family member, but they rarely engaged in such conversation with a member of their health care team. Agreement between patients' treatment preferences and their medical record documentation was only $30 \%$. Most discordance reflected their preferences for lessintensive management at the end of life when their medical records actually included plans for full cardiopulmonary resuscitation and technologic support in the event of life-threatening illness in hospital.

When asked about what features of quality end-of-life care they considered to be important, seriously ill Canadian patients in hospital and their family members highlighted trust in the treating physician, avoidance of unwanted life support, effective communication, continuity of care, and life completion. ${ }^{3}$ Customized approaches to improving an individual's care can be constructed by contrasting individual satisfaction ratings of elements of end-of-life care with the importance of those same elements. The Canadian Health Care Evaluation Project (CANHELP) questionnaire is a validated tool that can be used to measure satisfaction with end-of-life care. ${ }^{4}$ At a population level, juxtaposition of importance and satisfaction ratings can identify high priority targets for the quality improvement of our health care system. Preliminary evidence suggests that targets include more widespread strengthening of patient-physician relationships, enhanced communication and better decisionmaking, including advance care planning.

Advance care planning is an organized process of communication to help individuals and families understand, reflect upon and discuss the goals, values and beliefs for future health care decisions, particularly in the event of future inability to communicate. Advance care planning has the potential to increase patient-centred care by aligning patient preferences with the care they receive, while reducing caregiver burden and unwanted health care expenditures at life's end. Recently, 2 national initiatives have been launched to improve the quantity and quality of advance care planning in Canada: the "Speak Up" campaign, targeted toward the lay public, and the "Just Ask" campaign, targeted toward health care professionals. ${ }^{5}$

The preferences of some people for end-of-life care include a desire to die at home. Accordingly, many Canadians provide domestic care to dying family members or friends. Palliative caregiving can create treasured memories, profound intimacy and a deep sense of accomplishment. However, in one study, family caregivers felt unprepared and underresourced to minister palliative care in their homes. ${ }^{6}$ Short- and long-term depression, anxiety and posttraumatic stress disorder are prevalent in family members of decedents, but this can be ameliorated by timely, high-quality communication during the dying process. ${ }^{7}$

Further, the nature of some deaths may exceed caregivers' ability to cope while caring for their loved one at home. This often results in admission to hospital in the final months, weeks or days of life, underscoring the importance of institutional initiatives to improve end-of-life care. Another approach is residential hospice care, where the patient-family caregiver dyad is

\section{Key POINTS}

- Narrowing the gaps between the end-of-life care that patients prefer and what they actually receive should be a national priority.

- The quantity and quality of advance care planning needs to be improved.

- Burdens to family caregivers must be acknowledged and addressed.

- Physicians in training need more and better education about palliative care. 
the unit of care. As an alternate setting for patients unable to remain at home until death and for those who do not require or desire acute hospital care, hospices help to avoid the "medicalization of death," while offering holistic familycentred care, as well as ongoing symptom assessment and treatment.

Within a multidisciplinary team, physicians can play a pivotal role in providing quality endof-life care, wherever it occurs. Along with access to dedicated palliative care consultations and services, all practicing physicians need some skills in palliative care. The development of such skills is crucial for residents, who need more exposure encoded in their national training programs and adapted to their future roles, particularly given the incoming limited work hours and frequent handovers that will threaten the continuity of care. More so than didactic teaching, experiential, case-based, patient-centred curricula for hands-on learning about the practical and ethical aspects of palliative care may help to develop effective communication and counselling skills. Observing expert role models, receiving facilitated feedback and proceeding gradually toward supervised responsibility for leading such discussions ${ }^{8}$ should result in enhanced end-of-life care by future physicians.

Myriad statements and studies produced in Canada urge, on paper, efforts to enhance quality end-of-life care. Action is long overdue. More advance care planning, enhanced clinical programs for hospital, hospice and home-based endof-life care, and funding aligned with these mandates, as well as earlier and ongoing palliative care education are needed. More clinical and health services research will help to identify innovative, feasible, cost-effective strategies to optimize the dying experience. Sharing of existing successful local, provincial and national strategies could also help to advance the cause. ${ }^{9}$ Although personalized, compassionate and culturally sensitive end-of-life care may be a right of every Canadian, ${ }^{10}$ making it a reality requires more intense efforts by citizens, patients, providers and policy-makers working in concert toward this laudable goal.

\section{References}

1. Canadian Strategy of Palliative and End-of-Life Care. Ottawa (ON): Health Canada; 2007. Available: www.hc-sc.gc.ca/hcs-sss /alt_formats/hpb-dgps/pdf/pubs/2007-soin_fin-end_life/2007-soin -fin-end_life-eng.pdf (accessed 2013 July 23).

2. Heyland DK, Barwich D, Pichora D, et al.; for the ACCEPT Study Team and the Canadian Researchers at the End of Life Network (CARENET). Failure to Engage Seriously Ill Hospitalized Patients and Their Families in Advance Care Planning: Results of a multicentre prospective study. JAMA Intern Med. 2013;173:778-87.

3. Heyland DK, Dodek P, Rocker G, et al.; Canadian Researchers' End-of-Life Network (CARENET). What matters most in endof-life care: perceptions of seriously ill patients and their family members. CMAJ 2006; 174:627-33.

4. Heyland DK, Cook DJ, Rocker GM, et al. Defining priorities for improving end-of-life care in Canada. CMAJ 2010;182:E747-52.

5. Speak Up. Start the conversation about end of life care [homepage]. Ottawa (ON): Canadian Hospice Palliative Care Association; 2013. Available: www.advancecareplanning.ca (accessed 2013 July 23).

6. Stajduhar KI, Nickel DD, Martin WL, et al. Situated/being situated: Client and co-worker roles of family caregivers in hospice palliative care. Soc Sci Med 2008;67:1789-97.

7. Detering KM, Hancock AD, Reade MC, et al. The impact of advance care planning on end of life care in elderly patients: randomized controlled trial. BMJ 2010;340:c1345.

8. Stevens L, Cook DJ, Guyatt G, et al. Education, ethics and endof-life decisions in the intensive care unit. Crit Care Med 2002; 30:290-6.

9. Weiss A, Downar J. Ontario hospitals are not using palliative care performance indicators in their balanced scorecards. J Pain Symptom Manage 2013;46:e1-5.

10. Carstairs S, Beaudoin GA. Quality end of life care: the right of every Canadian. 2000; Ottawa (ON): Standing Senate Committee on Social Affairs, Science and Technology; 2000.

Affiliations: Departments of Medicine and Clinical Epidemiology and Biostatistics (Cook), McMaster University, Hamilton, Ont.; Department of Medicine (Rocker), Dalhousie University, Halifax, NS; Department of Medicine (Heyland), Queen's University, Kingston, Ont.

Contributors: Deborah Cook drafted the article, which was revised by Graeme Rocker and Daren Heyland. All of the authors approved the final version submitted for publication.

Acknowledgements: The authors thank Dr. Paul Armstrong for his helpful comments on this manuscript.

Some messages in this article were informed by a recent forum of the Canadian Academy of Health Sciences titled End of Life Care: the Last 100 Days. 